\title{
Functions of Peroxisome Proliferator-Activated Receptors (PPAR) in Skin Homeostasis
}

\author{
Nicolas Di-Poï, Liliane Michalik, Béatrice Desvergne, and Walter Wahli* \\ Center for Integrative Genomics, NCCR Frontiers in Genetics, University of Lausanne, CH-1015 Lausanne, Switzerland
}

\begin{abstract}
The peroxisome proliferator-activated receptors (PPAR) are ligand-activated transcription factors that belong to the nuclear hormone receptor family. Three isotypes (PPAR $\alpha$, PPAR $\beta$ or $\delta$, and PPAR $\gamma$ ) with distinct tissue distributions and cellular functions have been found in vertebrates. All three PPAR isotypes are expressed in rodent and human skin. They were initially investigated for a possible function in the establishment of the permeability barrier in skin because of their known function in lipid metabolism in other cell types. In vitro studies using specific PPAR agonists and in vivo gene disruption approaches in mice indeed suggest an important contribution of PPAR $\alpha$ in the formation of the epidermal barrier and in sebocyte differentiation. The PPAR $\gamma$ isotype plays a role in stimulating sebocyte development and lipogenesis, but does not appear to contribute to epidermal tissue differentiation. The third isotype, PPAR $\beta$, regulates the late stages of sebaceous cell differentiation, and is the most effective isotype in stimulating lipid production in these cells, both in rodents and in humans. In addition, PPAR $\beta$ activation has pro-differentiating effects in kera-tinocytes under normal and inflammatory conditions. Finally, preliminary studies also point to a potential role of PPAR in hair follicle growth and in melanocyte differentiation. By their diverse biological effects on cell proliferation and differentiation in the skin, PPAR agonists or antagonists may offer interesting oppotunities for the treatment of various skin disorders characterized by inflammation, cell hyperproliferation, and aberrant differentiation.

Paper no. L9545 in Lipids 39, 1093-1099 (November 2004).
\end{abstract}

Peroxisome proliferator-activated receptors (PPAR) belong, together with the receptors for thyroid hormones, retinoids, steroid hormones, and vitamin $\mathrm{D}$, to the nuclear hormone receptor family. They require heterodimerization with the retinoid $X$ receptors (RXR, NR2B) for binding to DNA as ligand-activated transcription factors that regulate the expression of target genes containing peroxisome proliferator response elements (PPRE) in their promoters. The PPAR subfamily consists of three isotypes, which are named PPAR $\alpha$ (NR1C1), PPAR $\beta$ or $\delta$ (NR1C2), and PPAR $\gamma$ (NR1C3). Each isoform is characterized by a distinct tissue distribution and

\footnotetext{
*To whom correspondence should be addressed at Center for Integrative Genomics (CIG), University of Lausanne, Biology Building, CH-1015 Lausanne, Switzerland. E-mail: walter.wahli@unil.ch

Abbreviations: ADRP, adipose differentiation-related protein; E, embryonic day; FIAF, fasting-induced adipose factor; PPAR, peroxisome proliferatoractivated receptor; PPRE, peroxisome proliferator response element; RXR, retinoid $\mathrm{X}$ receptor; TNF, tumor necrosis factor; TPA, tetradecanoylphorbol acetate.
}

specific functions (1). PPAR $\alpha$ has a main function in FA catabolism in the liver, and regulates amino acid metabolism, urea synthesis, and inflammatory responses $(1,2)$. PPAR $\gamma$ plays a pivotal role in adipocyte differentiation and then in maintenance of the differentiated state, as well as in lipid storage. Furthermore, like PPAR $\alpha$, it has been implicated in the downregulation of multiple inflammatory processes $(1,2)$. PPAR $\beta$ is the most ubiquitously expressed isotype, but little is known about its functions, mainly because of the lack, until recently, of selective PPAR $\beta$ agonists. Nevertheless, recent studies have suggested a role for PPAR $\beta$ in embryonic development, colon tumorigenesis, skin wound healing, fat catabolism, and oligodendrocyte differentiation $(3,4)$.

Specific roles for PPAR in vertebrate development have emerged from both in vitro and in vivo models, in particular during the differentiation of adipose tissue, brain, and placenta in mice (5). The importance of PPAR in lipid metabolism in various cell types has led to the investigation of PPAR expression and function during the differentiation of skin, which is a tissue with high rates of FA and cholesterol metabolism largely devoted to the formation of the epidermal permeability barrier. During skin development, several nuclear hormone receptors, including the estrogen, thyroid, androgen, and retinoid receptors, and their respective ligands have been implicated in the ontogeny of the epidermal barrier, hair follicle growth, and skin homeostasis $(6,7)$.

In this review, we will summarize the PPAR functions recently identified in skin homeostasis, including epidermal barrier formation, hair follicle growth, sebocyte differentiation, and melanogenesis.

\section{MAIN FUNCTIONS OF PPAR $\alpha$ AND PPAR $\beta$ IN THE HEALTHY AND INJURED EPIDERMIS}

The epidermis is renewed continuously and its integrity is dependent on a tightly regulated balance between cell proliferation, differentiation, and apoptosis. During its maturation, which happens mainly in the latest stages of fetal development, the epidermis evolves from a single layer of epithelial cells (periderm) to a fully stratified and differentiated epithelium (Fig. 1). This process involves the sequential expression of structural proteins (keratins, involucrin, loricrin, and filaggrin) and synthesis of specific lipids (sphingolipids, FFA, and cholesterol). The outermost layer of the epidermis, the stratum corneum, is the end product of keratinocyte differentiation and consists of a layer of cross-linked proteins and lipids, 
Periderm (E13.5)

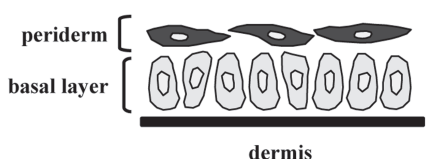

Stratified epidermis (newborn and adult)

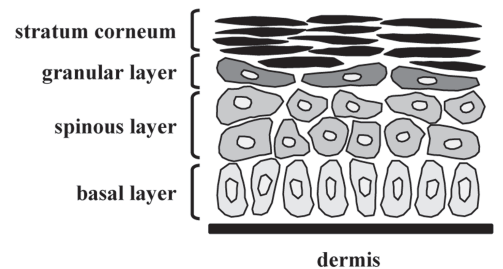

$\alpha, \beta$ and $\gamma$ in newborn, undetectable in adult

$\alpha$ and $\beta$ in newborn, undetectable in adult $\alpha, \beta$ and $\gamma$ detected in adult

FIG. 1. Schematic representation of interfollicular epidermis development. During late fetal development (between embryonic day E13.5 and the end of gestation) in mouse skin, the epidermis changes from a single basal undifferentiated layer (basal layer) covered by a transient superficial layer of cells (periderm), to a fully stratified and differentiated epithelium, with sequential formation of suprabasal layers (spinous and granular layers). The end product of differentiation resides on the surface of the epidermis (stratum corneum) and provides the main permeability barrier of the skin. Expression patterns of PPAR $\alpha(\alpha), \operatorname{PPAR} \beta(\beta)$, and PPAR $\gamma(\gamma)$ determined or not (nd) during mouse (3) and rat $(8,9)$ epidermal development, and in human adult interfollicular epidermis $(10,11)$, are summarized in the bottom panel.

which functions as a barrier to transepidermal water loss and as a defense against physical damage, microbes, and xenobiotics.

During mouse and rat embryonic development, all three PPAR isotypes, and predominantly PPAR $\beta$, have been detected in the interfollicular epidermis from embryonic day 13.5 (E13.5) onward $(3,8)$. Interestingly, PPAR expression is associated with all major events of the fetal maturation of the epidermal barrier. After birth, PPAR gradually disappear from the interfollicular epidermis to become undetectable in the adult animals (Fig. 1) (3,9). In contrast, the three PPAR isotypes are highly expressed in the basal and suprabasal layers of human adult interfollicular epidermis (Fig. 1), with PPAR $\beta$ being again the predominant subtype $(10,11)$. Consistent with the expression pattern of PPAR in the developing rodent skin, several reports have concentrated on the involvement of PPAR in processes such as cell proliferation, differentiation, and permeability barrier development (see Table 1). A variety of PPAR $\alpha$ activators, including clofibrate, were shown to accelerate the morphologic and functional maturation of the epidermal permeability barrier in fetal rat skin both in vitro and in vivo (12-14). This is evidenced by decreased transepidermal water loss, increased epidermal stratification, and increased expression of the two specific late keratinocyte differentiation markers, loricrin and filaggrin. PPAR $\alpha$ ligands also inhibit epidermal proliferation and induce keratinocyte differentiation in adult mouse epidermis in vivo $(15,16)$. Furthermore, these activators restore epidermal homeostasis in murine models of hyperproliferative epidermis (17). In contrast, the two PPAR $\gamma$ ligands, troglitazone and prostaglandin $\mathrm{J} 2$, did not affect the development of barrier function or epidermal morphology in fetal rat skin (12), and no specific function in skin maturation has been attributed so far to this isotype (Table 1). In favor of a potential role of PPAR $\beta$ in epidermal differentiation in rodents, the pan $\operatorname{PPAR}(\alpha / \beta)$ activator linoleic acid (18) was shown to accelerate epidermal barrier development in fetal rat skin explants (12). In addition, an important role of PPAR $\beta$ in mediating keratinocyte differentiation induced by inflammation was demonstrated in mouse primary keratinocytes (19). Importantly, the PPAR $\beta$-selective agonist GW1514 stimulated mouse epidermal differentiation without affecting cell proliferation in vivo, by inducing the expression of the late differentiation markers filaggrin and loricrin (20). Also, topical treatment of mice with GW1514 accelerates the restoration of permeability barrier functions after disruption by tape stripping, solvent, or detergent treatment (20), in support of the importance of the pro-differentiating effect of PPAR $\beta$ activation.

Novel information on the role of PPAR in epidermis homeostasis also came from PPAR mutant mouse models. Although normal skin architecture was initially reported in PPAR $\alpha$ knockout mice $(5,21)$, these animals show delayed fetal skin development between E18.5 and birth, with defects in the formation of the stratum corneum (22). Morphologic analysis of adult PPAR $\alpha$-null epidermis revealed a thinned stratum granulosum, with focal parakeratosis, indicative of impaired keratinocyte differentiation (15). Thus, consistent with its expression pattern, PPAR $\alpha$ might be important for the maturation of the epidermis during late embryogenesis, but dispensable for normal renewal of the epidermis in the adult animals. Interestingly, PPAR $\alpha$ also regulates the early inflammation phase during skin wound healing, as the recruitment of immune cells to the wound site is impaired in PPAR $\alpha$-null mice (3). PPAR $\gamma$ heterozygous mice, or PPAR $\gamma$-null mice born after placental rescue, show no defect in 
TABLE 1

Effects of Peroxisome Proliferator-Activated Receptor Agonists in Various Cell Types of the Skin ${ }^{a}$

\begin{tabular}{|c|c|c|c|}
\hline \multirow{2}{*}{$\frac{\text { Cell types }}{\text { Keratinocytes }}$} & & Rodents & Human \\
\hline & $\alpha$ & 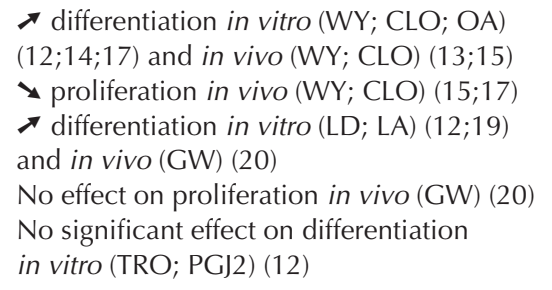 & 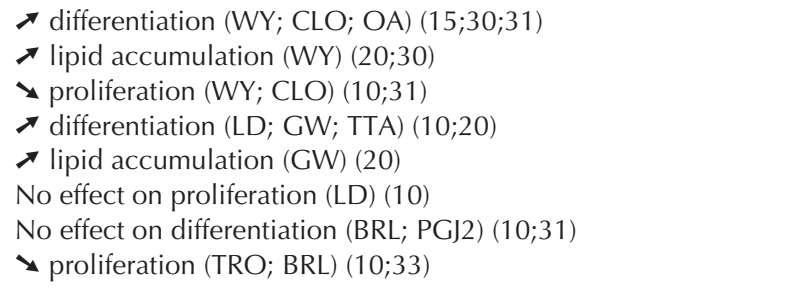 \\
\hline $\begin{array}{l}\text { Hair follicles } \\
\text { and melanocytes }\end{array}$ & $\alpha$ & $\begin{array}{l}\text { nd } \\
\text { nd }\end{array}$ & $\begin{array}{l}\boldsymbol{\nabla} \text { survival of cultured hair follicles (CLO) (34) } \\
\boldsymbol{y} \text { proliferation and } \boldsymbol{\nearrow} \text { melanogenesis in melanocytes (WY) (42) } \\
\text { No effect on proliferation and melanogenesis } \\
\text { in melanocytes (BEZ) (42) } \\
\boldsymbol{\nabla} \text { proliferation and } \boldsymbol{\nabla} \text { melanogenesis in melanocytes (CIG) (42) }\end{array}$ \\
\hline Sebocytes & $\alpha$ & $\begin{array}{l}\boldsymbol{\nearrow} \text { differentiation (WY) }(36 ; 37 ; 39) \\
\text { No effect on proliferation (WY) (39) } \\
\boldsymbol{\nearrow} \text { differentiation (LA; PGI2) }(36 ; 37 ; 39) \\
\boldsymbol{\nearrow} \text { proliferation (PGI2) (39) } \\
\boldsymbol{\nearrow} \text { differentiation (TRO; BRL) }(36 ; 37 ; 39) \\
\text { No effect on proliferation (TRO) (39) }\end{array}$ & $\begin{array}{l}\text { No effect on differentiation (WY) (38) } \\
\boldsymbol{\nearrow} \text { differentiation (LA) (38) } \\
\text { No effect on differentiation (CIG) (38) }\end{array}$ \\
\hline $\begin{array}{l}\text { entiation and proli } \\
\text { in in vitro studies, } \\
\text { ferentiation of hair } \\
\text { BEZ, bezafibrate; } \\
\text { baprostacyclin; PC }\end{array}$ & & $\begin{array}{l}\text { hulatory }(\boldsymbol{\nabla}) \text { or inhibitory }(\boldsymbol{\searrow}) \text { effects of treatm } \\
\text { arious cell types derived from rat and mouse ( } \\
\text { dent keratinocytes where both in vitro and in } \\
\text { melanocytes in rodents have not been deterr } \\
\text { 653; CIG, ciglitazone; CLO, clofibrate; GW, C } \\
\text { y-prostaglandin J2; TRO, troglitazone; TTA, te }\end{array}$ & $\begin{array}{l}t \text { with PPAR } \alpha(\alpha) \text {, PPAR } \beta(\beta) \text {, and PPAR } \gamma(\gamma) \text { agonists on the differ- } \\
\text { dents) as well as human (Human) skin. These results were obtained } \\
o \text { experiments were performed. Effects of PPAR ligands on the dif- } \\
\text { eed (nd). PPAR agonists used in each study are indicated as follows: } \\
1514 \text {; LA, linoleic acid; LD, L-165041; OA, oleic acid; PGI2, car- } \\
\text { decylthoacetic acid; WY, Wy-14,643. }\end{array}$ \\
\hline
\end{tabular}

epidermal maturation $(3,23)$. In addition, PPAR $\gamma$-null cells are able to participate in the formation of the epidermal tissue in PPAR $\gamma$-null and wild-type chimeric mice, suggesting very little or no contribution of PPAR $\gamma$ in this process (24). Analysis of PPAR $\beta$-mutant skin reveals no defect in fetal and adult epidermal architecture, or in the expression of keratinocyte differentiation markers (3). However, epidermal hyperplasia in response to tetradecanoylphorbol acetate (TPA) treatment was enhanced in PPAR $\beta$-mutant animals, emphasizing the role for PPAR $\beta$ in the control of keratinocyte proliferation and differentiation $(3,25)$. Similarly, the slightly increased keratinocyte proliferation index in PPAR $\beta$ heterozygous animals is also in favor of the existence of such a control (3). Consistent with these observations, PPAR $\beta$ expression is rapidly upregulated following challenges that stimulate keratinocyte proliferation, such as hair plucking or cutaneous injury, and skin wound healing is altered in PPAR $\beta$-mutant mice (3), largely due to a disrupted balance between proliferation and apoptosis $(19,26)$, as well as to defects in kera-tinocyte adhesion and migration $(3,27)$.

Important roles of PPAR $\alpha$ and PPAR $\beta$ in human keratinocyte differentiation were also reported (see Table 1). As already mentioned, PPAR $\beta$ is the predominant isotype in these keratinocytes $(10,11,28,29)$. Its expression remains high and unchanged during the differentiation of cultured keratinocytes, or during the stratification and keratinization of the epidermis in in vitro reconstructed skin $(10,28)$, whereas it increases upon squamous differentiation in human tracheobronchial epithelial cells (29). PPAR $\alpha$ and PPAR $\gamma$ are expressed at lower levels, but their expression increases upon keratinocyte differentiation in similar models $(10,28)$. In human keratinocytes, PPAR $\beta$ - (L-165041 and GW1514) and PPAR $\alpha$ (clofibrate and $\mathrm{Wy}-14,643$ )-selective agonists induce the expression of a number of epidermal differentiation markers, including involucrin (10,20,30), whereas PPAR $\gamma$ ligands (BRL-49653 and prostaglandin $\mathrm{J} 2$ ) have no effect $(10,31)$. The hypothesis that PPAR may also affect the metabolism of lipids in keratinocytes is supported by the observation that PPAR $\alpha$ ligand Wy-14,643 increased both the synthesis of cer-amides and cholesterol derivatives in a human skin equivalent model (30). Also, the PPAR $\beta$ selective agonist GW1514 increases TG accumulation and induces the adipose differentiation-related protein (ADRP) and fasting-induced adipose factor (FIAF) expression in human keratinocytes, two proteins that have potential important roles in lipid metabolism (20).

\section{IMPLICATION OF PPAR IN HYPERPROLIFERATIVE SKIN DISEASES}

Based on their diverse biological effects on keratinocyte proliferation and differentiation, PPAR ligands may become interesting compounds for the treatment of various epidermal disorders characterized by inflammation, keratinocyte hyperproliferation, and aberrant differentiation, such as psoriasis. In support of an involvement of PPAR in psoriatic epidermis, PPAR $\beta$ expression was reported to be dramatically increased in the hyperproliferative lesional skin from psoriatic patients $(11,28)$, probably as a response to pro-inflammatory signals in the lesions. It is indeed well established that PPAR $\beta$ gene 
expression is upregulated in mouse skin in response to inflammatory cytokines, such as tumor necrosis factor alpha $(\mathrm{TNF}-\alpha)$ (19). In addition, putative PPAR $\beta$ ligands, such as lipoxygenase products, are generated at high levels in psoriatic skin lesions, and may therefore activate the increased amount of PPAR $\beta$ (11). The fact that PPAR $\beta$ is probably naturally highly active in the psoriatic lesions may explain why the PPAR $\beta$ agonist tetradecylthioacetic acid has no strong antipsoriatic effect when applied topically (32). By contrast to PPAR $\beta$ expression, no or little change in the cutaneous levels of PPAR $\alpha$ and PPAR $\gamma$ was observed in lesional psoriatic skin $(11,28)$, and the PPAR $\alpha$ (clofibrate) and PPAR $\gamma$ (rosiglitazone) agonists had no effect when applied on psoriasis plaques (32). Nevertheless, it is encouraging to note that treatment with the synthetic PPAR $\gamma$ agonist troglitazone was reported to normalize the histological characteristics of psoriatic skin in organ culture, and to reduce the epidermal hyperplasia of psoriasis in the severe combined immunodeficient mouse and human skin transplant model of psoriasis (33). Finally, two PPAR $\alpha$ ligands (Wy-14,643 and clofibrate) were able to restore epidermal homeostasis in subacute and chronic models of hyperproliferative epidermis in hairless mice (17), even though these models do not perfectly mimic psoriatic or other human disorders. Obviously, further in vivo and clinical studies are needed to better define the potentially beneficial roles of PPAR in this pathology.

\section{ROLE OF PPARS IN HAIR FOLLICLE AND SEBOCYTE DIFFERENTIATION}

Skin epithelial progenitor cells give rise to the epidermis, as well as to the epithelial component of skin appendages, including hair follicles and their associated sebaceous glands. Hair follicle morphogenesis is governed by complex bidirectional interactions between epithelial keratinocytes and the underlying dermal cells of the mesenchymal condensations (Fig. 2). These interactions control a tight balance between keratinocyte proliferation and apoptosis. In rodents, all three PPAR isotypes are expressed in the differentiating hair follicles from the early embryonic developmental stages (Fig. 2). PPAR remain highly expressed in postnatal and adult hair follicles, whereas they disappear from the interfollicular epider-
E14.5

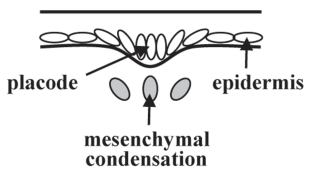

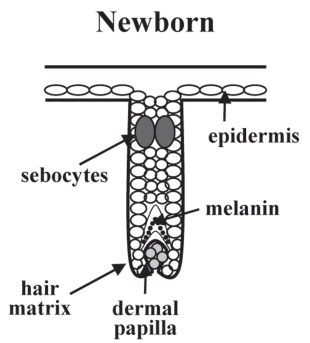

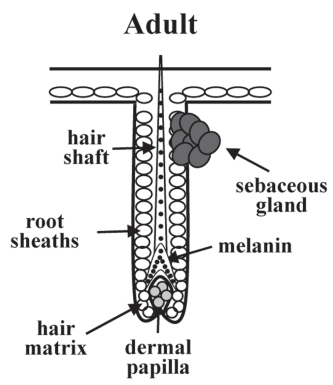

\begin{tabular}{|c|c|c|c|}
\hline Hair follicles: & E14.5 & Newborn & Adult \\
\hline Mouse: & $\alpha, \beta$ and $\gamma$ & $\alpha, \beta$ and $\gamma$ & $\alpha, \beta$ and $\gamma$ \\
\hline Rat: & nd & nd & $\alpha$ and $\beta$ ( $\gamma$ below detection) \\
\hline Human: & nd & nd & $\alpha, \beta$ and $\gamma$ \\
\hline Sebaceous glands & s: E14.5 & Newborn & Adult \\
\hline Mouse: & nd & nd & $\gamma(\alpha$ and $\beta$ not tested $)$ \\
\hline Rat: & nd & nd & $\alpha$ and $\beta$ ( $\gamma$ below detection) \\
\hline Human: & nd & nd & $\gamma(\alpha$ and $\beta$ not tested $)$ \\
\hline
\end{tabular}

FIG. 2. Schematic representation of murine hair follicle morphogenesis. Hair follicle development occurs between embryonic day 14.5 (E14.5) and postnatal day 7 (P7) in mouse, and is governed by bidirectional epithelial-mesenchymal interactions between epithelial keratinocytes and dermal fibroblasts of underlying mesenchymal condensations. Following dermal induction, hair follicle precursors appear first as thickening of the uniform epithelial surface (placode, E14.5). Follicular epithelial cells will next proliferate, followed by downgrowth into the dermis, leading to the elongation of hair follicles (Newborn), and will finally differentiate into the typical structures of mature hair follicles, including root sheaths, hair matrix, and hair shaft (Adult) (46). In parallel, melanin starts to be produced in the precortex region, and the first sebocytes form the sebaceous gland (Newborn). Expression patterns of PPAR $\alpha(\alpha)$, PPAR $\beta$ $(\beta)$, and PPAR $\gamma(\gamma)$ determined or not (nd) in mouse (8), rat (10), and human (35) hair follicles at indicated stages, as well as in mature sebaceous glands $(8,28,39)$, are given in the bottom panels. 
mis after birth $(3,8)$, as already mentioned (see Figs. 1, 2). A detailed analysis of the expression of PPAR in human hair follicles shows that they are specifically located in both epithelial and dermal hair follicle cells (34). In addition, the PPAR $\alpha$ ligand clofibrate was reported to increase the survival of human hair follicles in vitro, within a narrow range of concentrations (Table 1) (34). Although a possible function of the two other PPAR isotypes in hair follicle growth has not yet been examined, it is interesting to note that conditional ablation in the murine epidermis of $\operatorname{RXR} \alpha$, the most abundant heterodimeric partner of PPARs in keratinocytes, results in delayed hair follicle maturation and alopecia (35).

Chronologically, the latest differentiated cell type to appear in the developing follicle is the oil-rich sebocytes. They arise from cells within the superficial hair follicle and will eventually form a gland located outside the hair follicle. Sebaceous lipogenesis, leading to the accumulation of lipid droplets and finally to sebum excretion, represents a major step in the differentiation process and differentiated state of sebaceous gland cells. Rodent and human sebocytes were shown to express the three PPAR, either in cell culture or in vivo (Fig. 2), the predominant isotype being PPAR $\beta(9,24,36-$ 38). Consistently, and in addition to androgens that are well known to regulate the growth and maturation of sebocytes, PPAR agonists and retinoids were recently found to affect sebaceous gland differentiation (see Table 1). Activation of PPAR $\gamma$ and PPAR $\alpha$ by respective selective agonists has no effect on sebocyte growth (39), but stimulates lipid droplet accumulation in cultured rat preputial sebocytes, as assessed histochemically using Oil Red O staining $(36,37)$. This effect was not observed in epidermal cells (37) or in cultured human sebocytes (38), possibly due to the different selective PPAR agonists or to various ligand concentrations used in each study. In parallel, RXR selective ligands have prominent differentiative and weak proliferative effects on sebocytes (40). The RXR $\alpha$ selective rexinoid CD2809 also amplified the prodifferentiative effect of PPAR in preputial sebocytes, suggesting a cooperation between PPAR and RXR agonists in promoting differentiation of these cells (39). In both rat and human cultured sebocytes, the pan $\operatorname{PPAR}(\alpha / \beta)$ activators carbaprostacyclin and linoleic acid were more effective than PPAR $\alpha$ or PPAR $\gamma$ agonists in stimulating sebocyte lipid droplet formation, suggesting an important contribution of PPAR $\beta$ in this process (37-39). Interestingly, PPAR $\beta$ seems more important in the late stages of sebocyte differentiation $(37,38)$, whereas it was involved in the early adipocyte differentiation (41), suggesting that it plays different roles in the differentiation program of each cell type.

It is noteworthy that, in spite of the relative importance of PPAR in lipid metabolism and their high expression in sebocytes, in neither PPAR $\alpha$ nor PPAR $\beta$ mutant mouse models has sebaceous gland function been closely examined so far. In contrast, inactivation of the PPAR $\gamma$ gene has underscored a crucial contribution of PPAR $\gamma$ in sebocyte differentiation, although it appears dispensable for epidermal differentiation.
Indeed, and as already discussed, chimeric mice for PPAR $\gamma$ null and wild-type cells showed little or no contribution of mutant cells to the development of sebaceous glands, suggesting that PPAR $\gamma$-null cells cannot develop into sebocytes (24).

\section{NEW PUTATIVE FUNCTION OF PPARS IN MELANOCYTE DIFFERENTIATION}

The pigment-producing cells of the skin are called melanocytes and their activity is the major determinant of the color of the hair and skin. Melanocytes originate from the neural crest and migrate to the basal layer of the epidermis and the hair matrix during embryogenesis. Interestingly, all three PPAR were detected in cultured human melanocytes (42) and in melanoma cells (43). Consistent with the role of PPAR agonists in cellular proliferation and differentiation in keratinocytes, PPAR $\alpha$ (Wy-14,643) and PPAR $\gamma$ (ciglitazone) ligands were shown to inhibit the proliferation and to stimulate the melanin synthesis of cultured melanocytes (Table 1), whereas bezafibrate, a preferential activator for PPAR $\beta$ in Xenopus (44), had no effect on melanin content (42). In agreement with this study, several PPAR $\gamma$ agonists, including troglitazone and rosiglitazone, were previously demonstrated to inhibit cell growth in human malignant melanoma (43), and topical application of retinoic acid was shown to improve hyperpigmented skin lesions such as melasma (45). Because of their antiproliferative and prodifferentiative effect on melanocytes, it is tempting to suggest that PPAR and RXR ligands may be beneficial in the treatment of melanomas. However, too little is known in this context for the moment, and further investigation is needed.

\section{DISCUSSION AND HYPOTHESIS}

These studies suggest that PPAR $\alpha$ may contribute to sebaceous gland differentiation and epidermal permeability barrier formation by increasing both lipid metabolism and expression of structural differentiation markers, whereas PPAR $\gamma$ plays a unique role in stimulating sebocyte function. Furthermore, PPAR $\beta$ was identified as the predominant isotype in the skin, and as a modulator of cell differentiation in both keratinocytes and sebocytes.

Because of their diverse biological activities in epidermal processes such as keratinocyte proliferation and differentiation, PPAR may represent a major research target for the understanding and treatment of many skin diseases resulting in disturbance of normal tissue homeostasis and epidermal hyperproliferation, such as benign epidermal tumors, papillomas, melanomas, and psoriasis. In addition, due to the increasing number of studies implicating PPAR in the control of sebocyte differentiation, the development of PPAR antagonists that can interfere selectively with sebum production may constitute an important element in the prevention of acne vulgaris, characterized by excess sebum production. 


\section{ACKNOWLEDGMENTS}

This work was supported by the Swiss National Science Foundation (grants to Walter Wahli and to Béatrice Desvergne) and by the Etat de Vaud.

\section{REFERENCES}

1. Desvergne, B., and Wahli, W. (1999) Peroxisome ProliferatorActivated Receptors: Nuclear Control of Metabolism, Endocr. Rev. 20, 649-688.

2. Kersten, S., Desvergne, B., and Wahli, W. (2000) Roles of PPARs in Health and Disease, Nature 405, 421-424.

3. Michalik, L., Desvergne, B., Tan, N.S., Basu-Modak, S., Escher, P., Rieusset, J., Peters, J.M., Kaya, G., Gonzalez, F.J., Zakany, J., Metzger, D., Chambon, P., Duboule, D., and Wahli, W. (2001) Impaired Skin Wound Healing in Peroxisome Proliferator-Activated Receptor (PPAR) $\alpha$ and PPAR $\beta$ Mutant Mice, $J$. Cell Biol. 154, 799-814.

4. Michalik, L., Desvergne, B., and Wahli, W. (2003) Peroxisome Proliferator-Activated Receptors $\beta / \delta$ : Emerging Roles for a Previously Neglected Third Family Member, Curr. Opin. Lipidol. 14, 129-135.

5. Michalik, L., Desvergne, B., Dreyer, C., Gavillet, M., Laurini, R.N., and Wahli, W. (2002) PPAR Expression and Function During Vertebrate Development, Int. J. Dev. Biol. 46, 105-114.

6. Alonso, L.C., and Rosenfield, R.L. (2003) Molecular Genetic and Endocrine Mechanisms of Hair Growth, Horm. Res. 60, $1-13$.

7. Williams, M.L., Hanley, K., Elias, P.M., and Feingold, K.R. (1998) Ontogeny of the Epidermal Permeability Barrier, J. Investig. Dermatol. Symp. Proc. 3, 75-79.

8. Braissant, O., and Wahli, W. (1998) Differential Expression of Peroxisome Proliferator-Activated Receptor- $\alpha$, $-\beta$, and $-\gamma$ During Rat Embryonic Development, Endocrinology 139, 2748-2754.

9. Braissant, O., Foufelle, F., Scotto, C., Dauca, M., and Wahli, W. (1996) Differential Expression of Peroxisome Proliferator-Activated Receptors (PPARs): Tissue Distribution of PPAR- $\alpha,-\beta$, and $-\gamma$ in the Adult Rat, Endocrinology 137, 354-366.

10. Westergaard, M., Henningsen, J., Svendsen, M.L., Johansen, C., Jensen, U.B., Schroder, H.D., Kratchmarova, I., Berge, R.K., Iversen, L., Bolund, L., Kragballe, K., and Kristiansen, K. (2001) Modulation of Keratinocyte Gene Expression and Differentiation by PPAR-Selective Ligands and Tetradecylthioacetic Acid, J. Invest. Dermatol. 116, 702-712.

11. Westergaard, M., Henningsen, J., Johansen, C., Rasmussen, S., Svendsen, M.L., Jensen, U.B., Schroder, H.D., Staels, B., Iversen, L., Bolund, L., Kragballe, K., and Kristiansen, K. (2003) Expression and Localization of Peroxisome ProliferatorActivated Receptors and Nuclear Factor $\mathrm{\kappa B}$ in Normal and Lesional Psoriatic Skin, J. Invest. Dermatol. 121, 1104-1117.

12. Hanley, K., Jiang, Y., Crumrine, D., Bass, N.M., Appel, R., Elias, P.M., Williams, M.L., and Feingold, K.R. (1997) Activators of the Nuclear Hormone Receptors PPAR $\alpha$ and FXR Accelerate the Development of the Fetal Epidermal Permeability Barrier, J. Clin. Invest. 100, 705-712.

13. Hanley, K., Komuves, L.G., Bass, N.M., He, S.S., Jiang, Y., Crumrine, D., Appel, R., Friedman, M., Bettencourt, J., Min, K., Elias, P.M., Williams, M.L., and Feingold, K.R. (1999) Fetal Epidermal Differentiation and Barrier Development in vivo Is Accelerated by Nuclear Hormone Receptor Activators, J. Invest. Dermatol. 113, 788-795.

14. Komuves, L.G., Hanley, K., Jiang, Y., Elias, P.M., Williams, M.L., and Feingold, K.R. (1998) Ligands and Activators of Nuclear Hormone Receptors Regulate Epidermal Differentiation
During Fetal Rat Skin Development, J. Invest. Dermatol. 111, 429-433.

15. Komuves, L.G., Hanley, K., Lefebvre, A.M., Man, M.Q., Ng, D.C., Bikle, D.D., Williams, M.L., Elias, P.M., Auwerx, J., and Feingold, K.R. (2000) Stimulation of PPAR $\alpha$ Promotes Epidermal Keratinocyte Differentiation in vivo, J. Invest. Dermatol. $115,353-360$.

16. Hanley, K., Komuves, L.G., Ng, D.C., Schoonjans, K., He, S.S., Lau, P., Bikle, D.D., Williams, M.L., Elias, P.M., Auwerx, J., and Feingold, K.R. (2000) Farnesol Stimulates Differentiation in Epidermal Keratinocytes via PPAR $\alpha$, J. Biol. Chem. 275, 11484-11491.

17. Komuves, L.G., Hanley, K., Man, M.Q., Elias, P.M., Williams, M.L., and Feingold, K.R. (2000) Keratinocyte Differentiation in Hyperproliferative Epidermis: Topical Application of PPAR $\alpha$ Activators Restores Tissue Homeostasis, J. Invest. Dermatol. 115, 361-367.

18. Yu, K., Bayona, W., Kallen, C.B., Harding, H.P., Ravera, C.P., McMahon, G., Brown, M., and Lazar, M.A. (1995) Differential Activation of Peroxisome Proliferator-Activated Receptors by Eicosanoids, J. Biol. Chem. 270, 23975-23983.

19. Tan, N.S., Michalik, L., Noy, N., Yasmin, R., Pacot, C., Heim, M., Fluhmann, B., Desvergne, B., and Wahli, W. (2001) Critical Roles of PPAR $\beta / \delta$ in Keratinocyte Response to Inflammation, Genes Dev. 15, 3263-3277.

20. Schmuth, M., Haqq, C.M., Cairns, W.J., Holder, J.C., Dorsam, S., Chang, S., Lau, P., Fowler, A.J., Chuang, G., Moser, A.H., et al. (2004) Peroxisome Proliferator-Activated Receptor (PPAR)- $\beta / \delta$ Stimulates Differentiation and Lipid Accumulation in Keratinocytes, J. Invest. Dermatol. 122, 971-983.

21. Lee, S.S., Pineau, T., Drago, J., Lee, E.J., Owens, J.W., Kroetz, D.L., Fernandez-Salguero, P.M., Westphal, H., and Gonzalez, F.J. (1995) Targeted Disruption of the $\alpha$ Isoform of the Peroxisome Proliferator-Activated Receptor Gene in Mice Results in Abolishment of the Pleiotropic Effects of Peroxisome Proliferators, Mol. Cell Biol. 15, 3012-3022.

22. Schmuth, M., Schoonjans, K., Yu, Q.C., Fluhr, J.W., Crumrine, D., Hachem, J.P., Lau, P., Auwerx, J., Elias, P.M., and Feingold, K.R. (2002) Role of Peroxisome Proliferator-Activated Receptor $\alpha$ in Epidermal Development in Utero, J. Invest. Dermatol. 119, 1298-1303.

23. Barak, Y., Nelson, M.C., Ong, E.S., Jones, Y.Z., Ruiz-Lozano, P., Chien, K.R., Koder, A., and Evans, R.M. (1999) PPAR $\gamma$ Is Required for Placental, Cardiac, and Adipose Tissue Development, Mol. Cell 4, 585-595.

24. Rosen, E.D., Sarraf, P., Troy, A.E., Bradwin, G., Moore, K., Milstone, D.S., Spiegelman, B.M., and Mortensen, R.M. (1999) PPAR $\gamma$ Is Required for the Differentiation of Adipose Tissue in vivo and in vitro, Mol. Cell 4, 611-617.

25. Peters, J.M., Lee, S.S., Li, W., Ward, J.M., Gavrilova, O., Everett, C., Reitman, M.L., Hudson, L.D., and Gonzalez, F.J. (2000) Growth, Adipose, Brain, and Skin Alterations Resulting from Targeted Disruption of the Mouse Peroxisome Proliferator-Activated Receptor $\beta(\delta)$, Mol. Cell Biol. 20, 5119-5128.

26. Di Poï, N., Tan, N.S., Michalik, L., Wahli, W., and Desvergne, B. (2002) Antiapoptotic Role of PPAR $\beta$ in Keratinocytes via Transcriptional Control of the Akt1 Signaling Pathway, Mol. Cell 10, 721-733.

27. Di Poï, N., Michalik, L., Tan, N.S., Desvergne, B., and Wahli, W. (2003) The Anti-apoptotic Role of PPAR $\beta$ Contributes to Efficient Skin Wound Healing, J. Steroid Biochem. Mol. Biol. $85,257-265$.

28. Rivier, M., Safonova, I., Lebrun, P., Griffiths, C.E., Ailhaud, G., and Michel, S. (1998) Differential Expression of Peroxisome Proliferator-Activated Receptor Subtypes During the Differentiation of Human Keratinocytes, J. Invest. Dermatol. 111, $1116-1121$. 
29. Matsuura, H., Adachi, H., Smart, R.C., Xu, X., Arata, J., and Jetten, A.M. (1999) Correlation Between Expression of Peroxisome Proliferator-Activated Receptor $\beta$ and Squamous Differentiation in Epidermal and Tracheobronchial Epithelial Cells, Mol. Cell Endocrinol. 147, 85-92.

30. Rivier, M., Castiel, I., Safonova, I., Ailhaud, G., and Michel, S. (2000) Peroxisome Proliferator-Activated Receptor- $\alpha$ Enhances Lipid Metabolism in a Skin Equivalent Model, J. Invest. Dermatol. 114, 681-687.

31. Hanley, K., Jiang, Y., He, S.S., Friedman, M., Elias, P.M., Bikle, D.D., Williams, M.L., and Feingold, K.R. (1998) Keratinocyte Differentiation Is Stimulated by Activators of the Nuclear Hormone Receptor PPAR $\alpha$, J. Invest. Dermatol. 110, 368-375.

32. Kuenzli, S., and Saurat, J.H. (2003) Effect of Topical PPAR $\beta / \delta$ and PPAR $\gamma$ Agonists on Plaque Psoriasis. A Pilot Study, Dermatology 206, 252-256.

33. Ellis, C.N., Varani, J., Fisher, G.J., Zeigler, M.E., Pershadsingh, H.A., Benson, S.C., Chi, Y., and Kurtz, T.W. (2000) Troglitazone Improves Psoriasis and Normalizes Models of Proliferative Skin Disease: Ligands for Peroxisome Proliferator-Activated Receptor- $\gamma$ Inhibit Keratinocyte Proliferation, Arch. Dermatol. 136, 609-616.

34. Billoni, N., Buan, B., Gautier, B., Collin, C., Gaillard, O., Mahe, Y.F., and Bernard, B.A. (2000) Expression of Peroxisome Proliferator Activated Receptors (PPARs) in Human Hair Follicles and PPAR $\alpha$ Involvement in Hair Growth, Acta Derm. Venereol. 80, 329-334

35. Li, M., Chiba, H., Warot, X., Messaddeq, N., Gerard, C., Chambon, P., and Metzger, D. (2001) RXR- $\alpha$ Ablation in Skin Keratinocytes Results in Alopecia and Epidermal Alterations, Development 128, 675-688.

36. Rosenfield, R.L., Deplewski, D., Kentsis, A., and Ciletti, N. (1998) Mechanisms of Androgen Induction of Sebocyte Differentiation, Dermatology 196, 43-46.

37. Rosenfield, R.L., Kentsis, A., Deplewski, D., and Ciletti, N. (1999) Rat Preputial Sebocyte Differentiation Involves Peroxisome Proliferator-Activated Receptors, J. Invest. Dermatol. 112, 226-232.

38. Chen, W., Yang, C.C., Sheu, H.M., Seltmann, H., and
Zouboulis, C.C. (2003) Expression of Peroxisome ProliferatorActivated Receptor and CCAAT/Enhancer Binding Protein Transcription Factors in Cultured Human Sebocytes, J. Invest. Dermatol. 121, 441-447.

39. Kim, M.J., Deplewski, D., Ciletti, N., Michel, S., Reichert, U., and Rosenfield, R.L. (2001) Limited Cooperation Between Peroxisome Proliferator-Activated Receptors and Retinoid X Receptor Agonists in Sebocyte Growth and Development, Mol. Genet. Metab. 74, 362-369.

40. Kim, M.J., Ciletti, N., Michel, S., Reichert, U., and Rosenfield, R.L. (2000) The Role of Specific Retinoid Receptors in Sebocyte Growth and Differentiation in Culture, J. Invest. Dermatol. 114, 349-353.

41. Grimaldi, P.A. (2001) The Roles of PPARs in Adipocyte Differentiation, Prog. Lipid Res. 40, 269-281.

42. Kang, H.Y., Chung, E., Lee, M., Cho, Y., and Kang, W.H. (2004) Expression and Function of Peroxisome ProliferatorActivated Receptors in Human Melanocytes, Br. J. Dermatol. 150, 462-468.

43. Mossner, R., Schulz, U., Kruger, U., Middel, P., Schinner, S., Fuzesi, L., Neumann, C., and Reich, K. (2002) Agonists of Peroxisome Proliferator-Activated Receptor $\gamma$ Inhibit Cell Growth in Malignant Melanoma, J. Invest. Dermatol. 119, 576-582.

44. Krey, G., Braissant, O., L'Horset, F., Kalkhoven, E., Perroud, M., Parker, M.G., and Wahli, W. (1997) Fatty Acids, Eicosanoids, and Hypolipidemic Agents Identified as Ligands of Peroxisome Proliferator-Activated Receptors by CoactivatorDependent Receptor Ligand Assay, Mol. Endocrinol. 11, 779-791.

45. Kang, W.H., Chun, S.C., and Lee, S. (1998) Intermittent Therapy for Melasma in Asian Patients with Combined Topical Agents (Retinoic Acid, Hydroquinone and Hydrocortisone): Clinical and Histological Studies, J. Dermatol. 25, 587-596.

46. Paus, R., Muller-Rover, S., Van Der Veen, C., Maurer, M., Eichmuller, S., Ling, G., Hofmann, U., Foitzik, K., Mecklenburg, L., and Handjiski, B. (1999) A Comprehensive Guide for the Recognition and Classification of Distinct Stages of Hair Follicle Morphogenesis, J. Invest. Dermatol. 113, 523-532.

[Received July 19, 2004; accepted October 17, 2004] 